\title{
Effect of salt and temperature on the growth of Escherichia coli PSII
}

\author{
A. Medvedova* (), M. Kocis-Koval and L. Valik
}

Department of Nutrition and Food Quality Assessment, Faculty of Chemical and Food Technology, Slovak University of Technology, Radlinského 9, SK-81237 Bratislava, Slovakia

\section{ORIGINAL RESEARCH PAPER}

Received: July 28, 2020 • Accepted: November 01, 2020

Published online: March 24, 2021

(c) 2020 The Author(s)

\section{ABSTRACT}

Presence of pathogenic strains of Escherichia coli in foodstuffs may pose a health risk for a consumer. Therefore, knowledge on the effect of environmental factors on the growth ability of $E$. coli is of great importance. In this work, the effect of incubation temperature $\left(6-46^{\circ} \mathrm{C}\right)$ and the combined effect of temperature and water activity (0.991-0.930) on the growth dynamic of E. coli PSII were analysed. Based on the growth curves obtained, growth parameters were calculated by using the Baranyi D-model. Growth parameters were further analysed in secondary phase of predictive modelling. Using the CM model that describes the effect of combined factors, cardinal values $\left(T_{\min }=4.8 \pm 0.4^{\circ} \mathrm{C}\right.$, $T_{\text {opt }}=41.1 \pm 0.8{ }^{\circ} \mathrm{C}, T_{\max }=48.3 \pm 0.9{ }^{\circ} \mathrm{C}, a_{w \min }=0.932 \pm 0.001$, and $\left.a_{w \text { opt }}=0.997 \pm 0.003\right)$ for the isolate were calculated. Under optimal conditions, the specific growth rate is $\mu_{\mathrm{opt}}=2.84 \pm 0.08 \mathrm{~h}^{-1}$. The results obtained may contribute to the assessment of the risk associated with the possible E. coli presence in raw materials and to the search for preventive measures with defined degree of accuracy and reliability.

\section{KEYWORDS}

E. coli, predictive microbiology, water activity, temperature

\footnotetext{
${ }^{*}$ Corresponding author. Tel.: +421 259325488. E-mail: alzbeta.medvedova@stuba.sk
} 


\section{INTRODUCTION}

Escherichia coli as a pathogen in humans and animals is still of significant importance, since E. coli transmission through consumption of raw milk, raw milk dairy products, and minced meat has been repeatedly documented (EU Report, 2013). Though pathogenic strains in foods have low prevalence, saprophytic E. coli populations are more common, due to its common occurrence in the intestines of human and other mammals. Lues et al. (2003) and Chye et al. (2004) reported that $E$. coli was detected in $23-65 \%$ of raw milk samples ranging from $10^{4}$ to $10^{6}$ $\mathrm{CFU} \mathrm{mL}^{-1}$. Therefore, the limits for E. coli presence in dairy products were set by the EU Regulation No. 1441/2007: e.g., $100 \mathrm{CFU} \mathrm{g}^{-1}$ in cheeses manufactured from raw milk or heattreated whey; $10 \mathrm{CFU} \mathrm{g}{ }^{-1}$ in butter and cream; $50 \mathrm{CFU} \mathrm{g}{ }^{-1}$ in minced meat and separated meat;

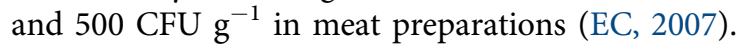

The fate of heat-labile E. coli in raw materials depends on many intrinsic and extrinsic environmental factors (Medvedová et al., 2018), including the interactions with other bacteria as described in our previous works (Ačai et al., 2019; Medvedová et al., 2020). However, some E. coli strains exhibit higher tolerance to adverse environmental conditions than other pathogenic and nonpathogenic microorganism. Such a tolerance is given by numerous factors, including production of stress-responding metabolites, harbour of resistance plasmid, and synthesis of protective surface appendages like colonic acid (Chen et al., 2004). In addition, in the case of osmotic stress that limits the availability of water for microbial cells, thus for enzyme functions and cell metabolism, other repair responses, such as production of chaperones and the induction of transport of ions (e.g. potassium glutamate), are immediately induced during lag-phase. Further, osmotic genes such as those corresponding to the osmoprotectant trehalose are expressed. Finally, at the end of lagphase and at beginning of exponential phase, a change of metabolism, a switch of metabolism from aerobic to anaerobic at a threshold $\mathrm{NaCl}$ concentration is observed (Métris et al., 2016).

In this context, our aim was quantify the growth ability of $E$. coli isolate based on cultivation experiments using predictive microbiology principles. Various predictive models were used to compare prediction precisions, and validation with external data was performed to define reliability of models to predict growth responses of food-origin isolate of E. coli.

\section{MATERIALS AND METHODS}

\subsection{Microorganism}

E. coli PSII was isolated from laboratory-produced pasta-filata cheese from raw cows' milk. Its identity was confirmed by a Gram staining, COLItest and ENTEROtest 24 (Lachema, Brno, Czechia), PCR method, and MALDI-TOF spectroscopy with score 2.397.

\subsection{Inoculation and cultivation conditions}

The isolate was kept in BHI broth (Sigma-Aldrich, St. Louis, USA) at $5 \pm 1{ }^{\circ} \mathrm{C}$ prior to analysis. Preparation of a standard suspension and inoculation was performed according to the study by 
Medvedová et al. (2018). The effect of temperature was studied in ultra-high temperaturetreated cows' milk (1.5\% fat content; Rajo, Bratislava, Slovakia), and the combined effect of temperature and $a_{w}$ was studied in PCA broth (Sigma-Aldrich, St. Louis, USA). The $a_{w}$ value was set to final value of $0.99 ; 0.97 ; 0.95$, and 0.93 by the addition of $\mathrm{NaCl}$, its actual value was measured by a LabMaster-aw (Novasina, Lachen, Switzerland). The static incubation of samples inoculated with isolate PSII was performed at $6,6.5,7,8,10,12,15,18,21,25,30,35,37,40,43$, and $46{ }^{\circ} \mathrm{C} \pm 0.5^{\circ} \mathrm{C}$, in three parallels.

\subsection{Enumeration of $E$. coli}

The actual counts of $E$. coli were determined at predefined time intervals with respect to the incubation temperature according to ISO 4833-1:2013 standard procedure with incubation at $37{ }^{\circ} \mathrm{C}$ to gain the growth curves.

\subsection{Fitting the growth curves and calculating the growth parameters}

The growth data, curves and parameters of the isolate were analysed, fitted, and calculated, respectively, using the mechanistic modelling technique of Baranyi and Roberts (1994). The growth response of $E$. coli PSII was plotted against time and fitted to a model for the estimation of the specific growth rate $(\mu)$ and maximal $\left(N_{\max }\right)$ density using an in-house Excel Add-in package 'DMFit' version 3.5 (ComBase managed by USDA ARS, Washington D.C., USA and University of Tasmania, Hobart, Australia).

\subsection{Secondary models}

The growth parameters from each individual growth curve were analysed in the secondary phase of modelling by statistic tools of Microsoft Office v. 2010 (Microsoft, Redmond, Washington, USA) and Statistica v. 10.0 data analysis software system (StatSoft, Tulsa, Oklahoma, USA). The specific growth rate $(\mu)$ as a function of temperature $(T)$ was modelled according to the Ratkowsky extended model (RTKext; Ratkowsky et al., 1983). Cardinal model (CM; Rosso et al., 1993) was used to describe the influence of $T$ or $a_{w}$ on specific growth rate. Finally, the combined effect of $T$ and $a_{w}$ based on individual cardinal models was determined according to the gamma concept (Zwietering et al., 1991).

\subsection{Model validation}

To validate the mathematical equations describing $E$. coli PSII responses to various $T$ and $a_{w}$ conditions, some mathematical and statistical indices were used. For the internal validation (model's precision to fit the experimental dataset of PSII isolate) standard error of prediction $(S E P)$, root mean square error (RMSE; Zurera-Cosano et al., 2006), and regression coefficient $\left(R^{2}\right)$ were calculated. For external validation (model's suitability, accuracy, and correctness to predict the $E$. coli growth) accuracy $\left(A_{f}\right)$ and bias $\left(B_{f}\right)$ factors (Baranyi et al., 1999) were calculated based on growth parameters dataset of E. coli BR isolate (Medvedová et al., 2018). In addition, the comparison (Fig. 2) was performed with ComBase (E. coli growth in broth), PMP (E. coli O157:H7 aerobic growth in broth), and MPV (non-pathogenic E. coli growth in milk) databases. 


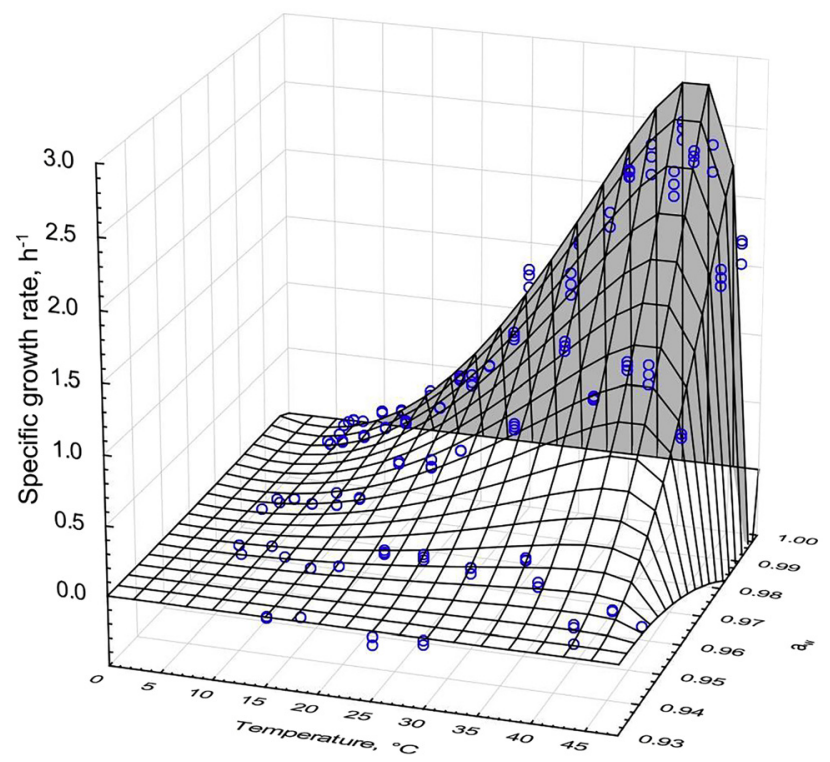

Fig. 1. Plots of the specific growth rates $(\mu)$ versus temperature $(T)$ and water activity $\left(a_{w}\right)$ for $E$. coli PSII. Symbols indicate calculated $\mu$ from growth curves at each $T$ and $a_{w}$ value. The network indicates fitted $\mu$ versus $\left(T, a_{w}\right)$ function according to gamma concept

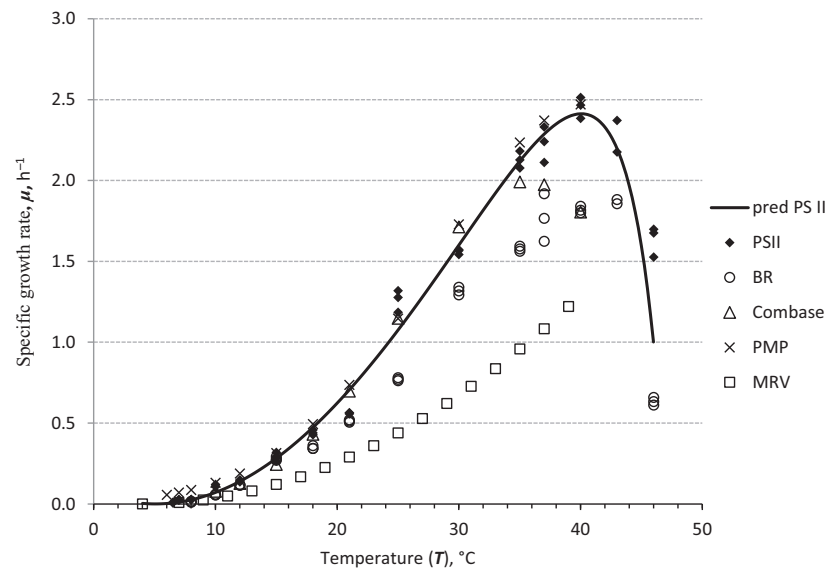

Fig. 2. The comparison of E. coli PSII ( growth in milk) modelled with CM model (continuous line) with E. coli $\mathrm{BR}(\mathrm{O}$ growth in milk), ComBase database ( $\Delta$ E. coli growth in broth), PMP database (x E. coli O157:H7 aerobic growth in broth), and MRV ( $\square$ non-pathogenic E. coli growth in milk) 


\section{RESULTS AND DISCUSSION}

In our previous work (Medvedová et al., 2018), the growth of two E. coli isolates (BR and LC) in milk as a function of incubation temperature by the use of predictive models was described. The Ratkowsky and CM models were suitable for estimation of $E$. coli growth dynamics. Consistent to study by Garre et al. (2020), where the strain variability in microbial responses to environmental factors was highlighted, we focused on describing the effect of temperature on the growth of E. coli PSII from pasta-filata cheese from raw cows' milk with the use of the above mentioned predictive models. Further, we described the effect of $a_{w}$ on E. coli PSII growth at the same temperatures.

\subsection{Effect of temperature on E. coli PSIl growth}

To compare the growth ability of $E$. coli PSII in the temperature range $6-46{ }^{\circ} \mathrm{C}$, it was necessary to inoculate with as constant initial counts as possible. The average initial E. coli PSII counts in all experiments were $3.1 \pm 0.4 \log \mathrm{CFU} \mathrm{mL} \mathrm{mL}^{-1}(\% V=12 ; n=48)$. All growth curves were characterised by typical sigmoid shape and were successfully fitted with the model of Baranyi and Roberts (1994) with the average of $R^{2}=0.978 \pm 0.058$. Obtained growth parameters are summarised in Table 1 . At $6{ }^{\circ} \mathrm{C}$, no growth of the isolate could be detected in 13 days; however, at $7{ }^{\circ} \mathrm{C}$, the increase of approximately $4 \log \mathrm{CFU} \mathrm{mL} \mathrm{m}^{-1}$ was observed. Therefore, the growth of the isolate at $6.5^{\circ} \mathrm{C}$ was also studied, with final counts being $0.9 \log \mathrm{CFU} \mathrm{mL} \mathrm{m}^{-1}$ lower compared to counts at $7{ }^{\circ} \mathrm{C}$. Further increase in incubation temperature led naturally to more intensive growth until $40{ }^{\circ} \mathrm{C}$ was reached, at which the maximal growth rate was obtained. Temperature

Table 1. Growth parameters of E. coli PSII in dependence on incubation temperature and $\mathrm{NaCl}$ addition

$\mu$ specific growth rate $\left(\mathrm{h}^{-1}\right)$ or $k$ inhibition rate

\begin{tabular}{|c|c|c|c|c|c|c|c|c|c|c|}
\hline \multirow[b]{2}{*}{$T\left({ }^{\circ} \mathrm{C}\right)$} & \multicolumn{5}{|c|}{$\left(\mathrm{h}^{-1}\right)$} & \multicolumn{5}{|c|}{$N_{\max }\left(\log \mathrm{CFU} \mathrm{mL}^{-1}\right)$} \\
\hline & $0 \%$ & $1.5 \%$ & $5 \%$ & $8 \%$ & $10 \%$ & $0 \%$ & $1.5 \%$ & $5 \%$ & $8 \%$ & $10 \%$ \\
\hline 6 & -0.02 & -0.01 & -0.01 & I & 1 & 1.4 & -3.0 & -1.4 & I & I \\
\hline 6.5 & 0.01 & -0.01 & -0.01 & I & 1 & 4.1 & -2.9 & -1.7 & I & I \\
\hline 7 & 0.03 & 0.03 & -0.01 & -0.01 & 1 & 7.2 & 4.3 & -2.2 & -2.1 & I \\
\hline 8 & 0.03 & 0.04 & -0.01 & -0.01 & 1 & 7.6 & 4.5 & -2.2 & -1.3 & 1 \\
\hline 10 & 0.11 & 0.08 & -0.01 & -0.01 & 1 & 8.6 & 5.3 & -2.6 & -2.2 & I \\
\hline 12 & 0.15 & 0.14 & $\begin{array}{r}-0.04 \\
0.05\end{array}$ & -0.01 & 1 & 8.5 & 5.0 & $\begin{array}{r}-1.3 \\
5.3\end{array}$ & -2.2 & 1 \\
\hline 15 & 0.29 & 0.29 & 0.10 & -0.02 & -0.03 & 8.5 & 5.3 & 4.1 & -2.6 & -1.5 \\
\hline 18 & 0.44 & 0.39 & 0.32 & 0.04 & -0.02 & 8.7 & 5.3 & 5.2 & 4.0 & -1.2 \\
\hline 21 & 0.56 & 0.59 & 0.29 & 0.05 & -0.03 & 8.9 & 5.2 & 5.2 & 4.0 & -1.6 \\
\hline 25 & 1.28 & 0.94 & 0.54 & 0.08 & -0.12 & 8.9 & 5.6 & 5.2 & 4.5 & -1.2 \\
\hline 30 & 1.57 & 1.32 & 0.74 & 0.04 & -0.01 & 8.7 & 5.4 & 5.0 & 4.7 & -1.4 \\
\hline 35 & 2.13 & 1.98 & 1.38 & 0.17 & -0.07 & 8.8 & 5.6 & 4.1 & 4.4 & -1.4 \\
\hline 37 & 2.33 & 2.28 & 0.95 & 0.08 & -0.62 & 8.7 & 5.2 & 5.0 & 3.6 & -1.7 \\
\hline 40 & 2.52 & 2.13 & 1.19 & -0.22 & -0.20 & 8.8 & 5.3 & 5.0 & -2.6 & -2.5 \\
\hline 43 & 2.37 & 2.45 & 1.25 & -0.16 & -0.46 & 8.5 & 5.3 & 5.5 & -2.0 & -2.4 \\
\hline 46 & 1.53 & 1.62 & 0.83 & * & -0.22 & 8.3 & 4.7 & 2.9 & * & -3.1 \\
\hline
\end{tabular}


above $40{ }^{\circ} \mathrm{C}$ resulted in a slowdown in growth dynamics. At 43 and $46{ }^{\circ} \mathrm{C}$, the decrease in growth rate by 6 and $30 \%$, respectively, was noticed. The growth rate at $46^{\circ} \mathrm{C}$ was comparable to growth rate at $30{ }^{\circ} \mathrm{C}$. In contrast, E. coli BR grew fastest at $43{ }^{\circ} \mathrm{C}$, and the growth rate at $46{ }^{\circ} \mathrm{C}$ was comparable to rate at $21{ }^{\circ} \mathrm{C}$ (Medvedová et al., 2018).

\subsection{Effect of water activity and temperature on E. coli PSII growth}

To study the effect of $a_{w}$ adjusted by $\mathrm{NaCl}$ addition to $1.5 \%\left(a_{w}=0.991 \pm 0.002 ; c_{v}=41 \% ; n=\right.$ 48); $5 \%\left(a_{w}=0.970 \pm 0.002 ; c_{v}=53 \% ; n=48\right) ; 8 \%\left(a_{w}=0.950 \pm 0.002 ; c_{v}=46 \% ; n=40\right)$, and $10 \%\left(a_{w}=0.930 \pm 0.002 ; c_{v}=43 \% ; n=24\right)$, the initial $E$. coli PSII counts were $3.07 \pm 0.48$ $\log \mathrm{CFU} \mathrm{mL} \mathrm{mL}^{-1}(\% \mathrm{~V}=16)$.

In case of $1.5 \% \mathrm{NaCl}$ addition, E. coli PSII at $7{ }^{\circ} \mathrm{C}$ only started to grow after 21 days, but its final counts and the growth rate were higher about $14 \%$ than in the medium without added $\mathrm{NaCl}$. Similarly, at 8,43 , and $46^{\circ} \mathrm{C}$, the addition of $\mathrm{NaCl}$ led to higher growth rates by 30,4 , and $6 \%$, respectively. It may be a result of $E$. coli response to osmotic stress on the membrane that induced production of chaperones and the induction of transport ions (Métris et al., 2016). Moreover, accumulation of compatible solutes (betain, prolin, etc.) at lower $a_{w}$ values can support more intensive growth of E. coli (O’Byrne and Booth, 2002) compared to its growth in the medium without added $\mathrm{NaCl}$.

With $5 \% \mathrm{NaCl}$ addition, E. coli PSII growth could be observed at temperatures above $12{ }^{\circ} \mathrm{C}$. However, at $12{ }^{\circ} \mathrm{C}$, first an inhibition after $80 \mathrm{~h}$ was observed, and only after further 11 days it started to grow to a final density of $7 \log \mathrm{CFU} \mathrm{mL} \mathrm{m}^{-1}$. In temperature range from 15 to $46^{\circ} \mathrm{C}$ the growth was slower by $30-66 \%$ compared to growth at $1.5 \% \mathrm{NaCl}$ addition.

At $8 \% \mathrm{NaCl}$ addition, the growth of E. coli PSII could only be detected from 18 to $40{ }^{\circ} \mathrm{C}$. The growth was slower by $83-94 \%$ compared to its growth at $5 \% \mathrm{NaCl}$ addition. Interestingly, at $46{ }^{\circ} \mathrm{C}$, the viable cell concentration decreased with $k=-0.20 \mathrm{~h}^{-1}$ immediately after inoculation to a level of $0.4 \log \mathrm{CFU} \mathrm{mL} \mathrm{m}^{-1}$. However, after $20 \mathrm{~h}$, bacteria started to grow with $\mu=0.88 \mathrm{~h}^{-1}$ to $1.3 \log \mathrm{CFU} \mathrm{mL} \mathrm{m}^{-1}$ concentration, which was maintained for $80 \mathrm{~h}$, then started to decrease again with $k=-0.01 \mathrm{~h}^{-1}$. As such a complicated process was observed in this case, a symbol * is used in Table 1.

Finally, at $10 \% \mathrm{NaCl}$ addition, growth inhibition of the isolate was observed during the whole experiment, thus those values were excluded from secondary modelling.

\subsection{Secondary modelling and validation}

From 3 parallel primary growth curves, the specific growth rate $(\mu)$ and maximum counts in stationary phase $\left(N_{\max }\right)$ were derived by DMfit tools, and their average values at each temperature are summarised in Table 1 . Individual data were subsequently used in secondary phase of predictive modelling to describe the influence of selected factors on microbial growth.

To predict the effect of incubation temperature on the specific growth rate of E. coli PSII at selected $\mathrm{NaCl}$ addition or without $\mathrm{NaCl}$, the $\mathrm{RTK}_{\text {ext }}$ model and the $\mathrm{CM}$ model were used. The advantage of the CM model is that it provides not only $T_{\min }$ and $T_{\max }$ calculations (as in case of

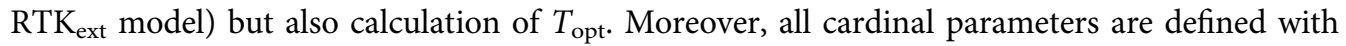
the simple biological meaning, since the settings of the model parameters are based on their biological interpretation with lack of structural correlation between them (Rosso et al., 1993). Based on these models, cardinal temperatures, presented in Table 2, were calculated. At the 
$\mathrm{RTK}_{\text {ext }}$ model by $44.8 \%\left(A_{f}=1.448, B_{f}=1.350\right)$ and in case of CM model by $37.6 \%\left(A_{f}=1.376\right.$, $B_{f}=1.323$ ); however, it provides options for preventive measures to be taken during production of risky foods. Comparing the growth data obtained from ComBase database (growth of nonpathogenic E. coli in broth) and MRV database (growth of non-pathogenic E. coli in milk), the $\mathrm{CM}$ model overestimates the parameters obtained. In the case of the growth of pathogenic E. coli O157:H7 in broth, comparable specific growth rate values were found in PMP database. Taking this into account, the predictions based on PSII isolate will be reliable and will reliably provide $E$. coli responses to changing environmental factors, especially temperature, water activity, and their mutual combinations.

\section{CONCLUSIONS}

The growth of E. coli PSII isolated from pasta-filata cheese from raw cows' milk was described in dependence on temperature $\left(6-46^{\circ} \mathrm{C}\right)$ and $\mathrm{NaCl}$ addition $(1.5,5,8,10 \%)$ by the use of predictive models. Based on $\mathrm{RTK}_{\text {ext }}$, CM model, and gamma concept, the cardinal values for the E. coli PSII growth were defined as $T_{\min }=4.8 \pm 0.4{ }^{\circ} \mathrm{C}, T_{\text {opt }}=41.1 \pm 0.8{ }^{\circ} \mathrm{C}, T_{\max }=48.3 \pm 0.9{ }^{\circ} \mathrm{C}$, $a_{w \min }=0.932 \pm 0.001$, and $a_{w \mathrm{opt}}=0.997 \pm 0.001$. At optimal conditions, the isolate grows with $\mu=2.84 \mathrm{~h}^{-1}\left(t_{d}=14.6 \mathrm{~min}\right)$. Based on validation factors and mathematical indices, all models used are suitable for the estimation of growth dynamic of $E$. coli and can be applied to shelf-life estimations of selected foods.

\section{ACKNOWLEDGEMENT}

This work was supported by the contract of VEGA, No. 1/0532/18 and APVV-19-0031. We also thank J. Baranyi for providing DMFit Tools.

\section{REFERENCES}

Ačai, P., Medveďová, A., Mančušková, T., and Valík, L'. (2019). Growth prediction of two bacterial populations in co-culture with lactic acid bacteria. Food Science and Technology International, 25: 692-700.

Baranyi, J., Pin, C., and Ross, T. (1999). Validating and comparing predictive models. International Journal of Food Microbiology, 48: 159-166.

Baranyi, J. and Roberts, T.A. (1994). A dynamic approach to predicting bacterial growth in food. International Journal of Food Microbiology, 23: 277-294.

Chen, J., Lee, S.M., and Mao, Y. (2004). Protective effect of exopolysaccharide colonic acid of E. coli O157: H7 to osmotic and oxidative stress. International Journal of Food Microbiology, 93: 281-286.

Chye, F.Y., Abdullah, A., and Ayob, M.K. (2004). Bacteriological quality and safety of raw milk in Malaysia. Food Microbiology, 21: 535-541.

ComBase database. Available at https://www.combase.cc/index.php/en/ (last accessed 7 October 2020).

EC. (2007). Commission Regulation (EC) No 1441/2007 amending Regulation (EC) No 2073/2005 on microbiological criteria for foodstuffs. Official Journal of the European Union, 2007: 18. 
EU Report. (2013). The European Union summary report on trends and sources of zoonoses, zoonotic agents and food-borne outbreaks in 2011 (2013). EFSA Journal, 11 [cit. 26. 10. 2016].

Garre, A., Zwietering, M.H., and den Besten, H.M.W. (2020). Multilevel modelling as a tool to include variability and uncertainty in quantitative microbiology and risk assessment. Thermal inactivation of $L$. monocytogenes as a proof concept. Food Research International, 137: 109374.

ISO. (2013). Horizontal method for the enumeration of microorganisms. ISO 4833-1:2013.

Lues, J.F.R., Venter, P., and van der Westhuizen, H. (2003). Enumeration of potential microbiological hazards in milk from a marginal urban settlement in central South Africa. Food Microbiology, 20: 321-326.

Medvedová, A., Györiová, R., Lehotová, V., and Valík, Ľ. (2020). Co-cultivation growth of Escherichia coli and Staphylococcus aureus as two common dairy contaminants. Polish Journal of Food and Nutrition Sciences, 70: 151-157.

Medveďová, A., Rosskopf, F., Liptáková, D., and Valík, Ľ. (2018). Prediction of temperature effect on growth of two raw milk cheeses isolates of E. coli in milk. Journal of Food and Nutrition Research, 57: $141-150$.

Métris, A., George, S., and Baranyi, J. (2016). A dynamic network analysis of the physiological state of foodborne pathogens: application to E. coli during osmotic stress and comparison with Salmonella Typhimurium. Procedia Food Science, 7: 21-24.

Microbial response viewer (MRV). Available at http://mrviewer.info/\# (last accessed 7 October 2020).

O’Byrne, C.P. and Booth, I.R. (2002). Osmoregulation and its importance to food-borne microorganisms. International Journal of Food Microbiology, 74: 203-216.

Pathogen Modeling Program (PMP) Online. Available at https://pmp.errc.ars.usda.gov/default.aspx (last accessed 7 October 2020).

Ratkowsky, D.A., Lowry, R.K., McMeekin, T.A., Stokes, A.N., and Chandler, R.E. (1983). Model for bacterial culture growth rate throughout the entire biokinetic temperature range. Journal of Bacteriology, 154: $1222-1226$.

Rosso, L., Lobry, J., and Flanders, J. (1993). Unexpected correlation between temperatures of microbial growth highlighted by new model. Journal of Theoretical Biology, 162: 447-463.

Salter, M.A., Ross, T., and McMeekin, T.A. (1998). Applicability of a model for non-pathogenic Escherichia coli for predicting the growth of pathogenic Escherichia coli. Journal of Applied Microbiology, 85: 357-364.

Sommers, Ch., Huang, Ch.Y., Sheen, L.Y., Sheen, S., and Huang, L. (2018). Growth modelling of uropathogenic E. coli in ground chicken meat. Food Control, 86, 397-402.

Van Derlinden, E. and Van Impe, J.F. (2012). Modeling growth rates as a function of temperature. International Journal of Food Microbiology, 158, 73-78.

Wang, G., Zhao, T., and Doyle, M.P. (1997). Survival and growth of E. coli O157:H7 in unpasteurized and pasteurized milk. Journal of Food Protection, 60, 610-613.

Zurera-Cosano, G., Garciá-Gimeno, R.M., Rodríguez-Pérez, R., and Hervás-Martínez, C. (2006). Performance of response surface model for prediction of $L$. mesenteroides growth parameters under different experimental conditions. Food Control, 17: 429-438.

Zwietering, M.H., De Koos, J.T., Hasenack, B.E., De Wit, J.C. and Riet, K. (1991). Modelling of bacterial growth as a function of temperature. Applied and Environmental Microbiology, 57: 1094-1101.

Open Access. This is an open-access article distributed under the terms of the Creative Commons Attribution-NonCommercial 4.0 International License (https://creativecommons.org/licenses/by-nc/4.0/), which permits unrestricted use, distribution, and reproduction in any medium for non-commercial purposes, provided the original author and source are credited, a link to the CC License is provided, and changes - if any - are indicated. 